\title{
Short-term precision error in dual energy $x$-ray absorptiometry, bone mineral density and trabecular bone score measurements; and effects of obesity on precision error
}

\author{
Susan J Hopkins, J oanne R Welsman, Karen M Knapp \\ Department of Medical Imaging, College of Engineering, Mathematics and Physical Sciences, University of Exeter, Exeter, \\ UK
}

Correspondence: Susan J Hopkins. Address: University of Exeter, 205 Physics Building, Stocker Road, Exeter EX4 4QL, UK. E-mail: sjh256@exeter.ac.uk

Received: October 20, 2013

Accepted: January 20, 2014

Online Published: February 8, 2014

DOI : $10.5430 / j b g c . v 4 n 2 p 8$

URL: http://dx.doi.org/10.5430/jbgc.v4n2p8

\section{Abstract}

Introduction: Bone mineral density (BMD) measured by dual energy $\mathrm{x}$-ray absorptiometry (DXA) is the primary screening tool for diagnosis of osteopenia and osteoporosis. BMD alone does not provide information regarding the structural characteristics of bone and this limitation has been a driver for the development of techniques, including trabecular bone score (TBS) software, to assess bone microarchitecture. Precision error in DXA is important for accurately monitoring changes in BMD and it has been demonstrated that BMD precision error increases with increasing body mass index (BMI). Information on in vivo precision error for TBS is very limited. This study evaluated short-term precision error (STPE) of lumbar spine BMD \& TBS measurement, and investigated the effect of obesity on DXA precision error.

Method: DXA lumbar spine scans (L1-L4) were performed using GE Lunar Prodigy. STPE was measured in ninety-one women at a single visit by duplicating scans with repositioning in-between. Precision error was calculated as the percentage coefficient of variation. Participants were sub-divided into four groups based on BMI to assess the effect of obesity on STPE.

Results: STPE is poorer for TBS than for BMD. STPE is adversely affected for both BMD and TBS measurements by increasing BMI but this effect is mitigated for TBS in the highest BMI category where use of the thick scanning mode improves signal to noise ratio.

Conclusion: Results from serial BMD and TBS measurements should take account of differences in precision error in the two techniques and in different BMI categories.

\section{Key words}

Precision error, Bone mineral density, Trabecular bone score, Obesity, Body mass index

\section{I ntroduction}

Bone mineral density (BMD) measured by dual energy x-ray absorptiometry (DXA) is currently the primary screening tool for clinical diagnosis of osteopenia and osteoporosis on the basis of its relatively low cost, convenience for patients, 
short scan times and minimal radiation dose ${ }^{[1]}$. DXA may be used to measure BMD at any skeletal site but it is typically used to measure posterior/anterior lumbar spine and the proximal femur region of interest (ROI) as these are the most clinically relevant in terms of fracture incidence and severity ${ }^{[2]}$. BMD does however have acknowledged limitations for fracture prediction as a large overlap in the BMD of patients who do or do not sustain fractures has been demonstrated ${ }^{[3]}$. Sornay-Rendu et al. ${ }^{[4]}$ showed that $48 \%$ of women who sustained a fragility fracture had a baseline BMD in the osteopenic range and $8 \%$ were in the normal range. The mechanical efficiency of bone is not solely dependent on the quantity of accumulated material (bone mineral content) but also on the optimisation of the spatial distribution of that material ${ }^{[5]}$. The external and internal architectures of bones are both important factors in the distribution and transmission of loads, and have a significant effect on how fractures initiate and propagate throughout the material ${ }^{[6]}$. A combination of structural and densotomic indices potentially provide a more accurate assessment of bone quality and fragility that may improve sensitivity and/or specificity to identify individuals at heightened fracture risk ${ }^{[7]}$.

Bone structural parameters are not currently assessed as part of routine clinical practice and although methodologies, such as high resolution quantitative computed tomography (QCT) and magnetic resonance imaging (MRI), have the capability to provide this information, their use is not practical in clinical situations. The known limitations of standard densitometry have been a driver for the development of techniques to assess bone microarchitecture. Boehm et al. ${ }^{[8]}$ investigated the topological properties of bone mineral distribution patterns from images generated during conventional DXA hip scanning to test the ability of this method to discriminate between postmenopausal women with hip fracture and controls. In a study population of 100, of whom 50 were hip fracture patients, they found $71 \%-84 \%$ of patients were correctly identified by regional topological analysis compared to $58 \%-68 \%$ identified by BMD. Using a similar principle, based on two dimensional DXA image analysis, software has been developed to provide a trabecular bone score (TBS iNsight ${ }^{\mathbb{B}}, \mathrm{v} 1.8$. Med-Imaps, France) for assessment of the lumbar spine ROI.

TBS is a grey-level texture measurement that provides an assessment of bone quality using two-dimensional (2D) projection images derived from the same raw DXA data that provide the BMD measurement. It is based on the use of experimental variograms and is able to differentiate between two 3D micro-architectures that exhibit the same bone density but different trabecular characteristics ${ }^{[9,10]}$. A number of studies have evaluated the use of TBS to predict osteoporotic fractures independently of BMD ${ }^{[11-14]}$. Hans et al. ${ }^{[14]}$ demonstrated that TBS and BMD have equal discrimination to predict osteoporotic spine and hip fractures, and that this is improved by a combination of both. TBS potentially provides a technological development that could be readily incorporated into clinical routine to complement BMD information and enhance fracture prediction.

Precision error (PE) in DXA is important for the accurate monitoring of longitudinal changes in BMD. DXA has stable calibration and high precision ${ }^{[2]}$ but a number of issues should be considered when interpreting results from repeat scans. Variation in a participant's positioning for repeat scans can cause measurement error and it is therefore desirable to use the same operator to avoid inter-operator differences in positioning technique. As biological changes in BMD are generally small relative to the error inherent in the test itself, interpretation of serial BMD tests depends on knowledge of the least significant change (LSC) in BMD that is beyond the range of error ${ }^{[15]}$.

In clinical terms, true change is based on a LSC of $2.8 \%$, generally assuming precision error of $1 \%{ }^{[16]}$. Higher body mass index (BMI) has been demonstrated to contribute to increased DXA precision error that may be attributable to greater tissue inhomogeneity at the site of the lumbar spine and a reduction in signal to noise ratio in larger participants ${ }^{[17]}$. Whilst short-term precision has been reported for DXA BMD measurement ${ }^{[18,22]}$ information is very limited regarding in vivo short-term precision error (STPE) for TBS ${ }^{[19]}$. This study investigated the STPE of TBS and BMD and the effect of obesity on precision error. 


\section{Method}

\subsection{Participants}

Data were analysed from ninety one participants (Group A) recruited for a precision study ${ }^{[18]}$ in which female volunteers aged 18 years to 75 years were recruited from the general population. Participants were recruited by a poster and leaflet campaign and no exclusion criteria were applied other than contradictions for DXA scanning and the presence of metallic implants. Group A was sub-divided into four groups based on BMI: A.1: $<25 \mathrm{~kg} / \mathrm{m}^{2}(\mathrm{n}=41)$, A.2: $25 \mathrm{~kg} / \mathrm{m}^{2}-29.9 \mathrm{~kg} / \mathrm{m}^{2}$ $(\mathrm{n}=25)$, A. $3: 30 \mathrm{~kg} / \mathrm{m}^{2}-35 \mathrm{~kg} / \mathrm{m}^{2}(\mathrm{n}=15)$, and A.4: $>35 \mathrm{~kg} / \mathrm{m}^{2}(\mathrm{n}=10)$, to assess the effect of obesity on STPE. The first three categories reflect the World Health Organisation (WHO) criteria for normal, overweight, and obese respectively; group A.4 was separately selected as this is above of the BMI range currently recommended for TBS analysis by its designers.

Informed written consent was obtained for all participants and the study was approved by the Devon and Torbay Research Ethics Committee.

\subsection{Methods}

Before scanning, the participant's height was measured $( \pm 0.01 \mathrm{~m})$ using a stadiometer (Holtain, Crymych, Dyfed, UK) and body weight measured $( \pm 0.1 \mathrm{~kg}$ ) using beam balance scales (Avery, Birmingham, UK). DXA lumbar spine scans (L1-L4) were performed using GE Lunar Prodigy (Bedford UK). Participants were scanned on a single visit and scans were duplicated with repositioning in-between i.e. dismounting the scanner and returning to the same position after walking briefly around the room. Standard or thick scan modes, based on participant's BMI, were automatically selected by the scanner software. Twenty-nine successive L1-L4 measurements were performed on an aluminium spine phantom (GE Lunar) during the period of the study, (approximately once per week) to determine the coefficient of variation of the DXA equipment.

\subsection{Statistics}

BMI was calculated as weight $(\mathrm{kg}) /$ height $\left(\mathrm{m}^{2}\right)$. GE Lunar Encore 2005 (v. 9.30.044) software was used to analyse the DXA raw data to obtain BMD measurements. TBS (TBS iNsight ${ }^{\mathbb{B}}$ ) was applied retrospectively to the same raw data using identically defined ROIs to obtain trabecular bone scores. Abnormally different vertebrae were excluded from the analysis in accordance with The International Society for Clinical Densitometry (ISCD) recommendations ${ }^{[20]}$. Means and standard deviations were calculated (Microsoft Excel 97-2003) for participant characteristics and densitometry measurements. Means, adjusted for the effect of age as a covariate, were calculated by Univariate Analysis of Variance (PASW Statistics 18). Pearsons correlations were calculated between BMI \& BMD, BMI \& TBS and BMD and TBS (PASW Statistics 18). PE was reported as the root mean square coefficient of variation (RMSCV\%) between original and duplicate scans, calculated as the root mean square standard deviation (RMSSD) as a percentage of the mean BMD or TBS measurement. Significance of differences between the BMI sub-groups was calculated by independent $t$ tests (PASW Statistics 18.). PE for the spine phantom was calculated as the percentage coefficient of variation (CV\%) between twenty-nine sets of duplicate scans.

\section{Results}

Table 1 shows the participant characteristics and the lumbar spine BMD and TBS measurements for the various groups. The BMI sub-groups were well matched, with no significant differences for mean age, height, lumbar spine BMD and TBS except for group A.3 who were significantly older with lower mean TBS scores compared to the normal BMI group. As there is an age difference between the groups, the results have also been reported (see Table 1 - Table 3) as adjusted means to account for age as a covariate to the effects of BMI on either BMD or TBS scores. No significant effect was 
found for age as a covariate in Groups A.3 and the difference between the means and adjusted means is minimal; it is inferred that the difference in the age of Group A.3 has minimal effect on the BMD and TBS values of this obese category.

Table 1. Participant characteristics (scan 1)

\begin{tabular}{|c|c|c|c|c|c|}
\hline \multirow{2}{*}{ Group } & $\overline{\mathbf{A}}$ & A.1 & A.2 & A.3 & A.4 \\
\hline & Whole group & Optimum & Overweight & Obese & $>35 \mathrm{~kg} / \mathrm{m}^{2}$ \\
\hline $\mathrm{n}$ & 91 & 41 & 25 & 15 & 10 \\
\hline \multirow[t]{2}{*}{ Thick scan mode (\% of group) } & 12.0 & 0.0 & 0.0 & 14.3 & 90.0 \\
\hline & & & Mean $(S D)$ & & \\
\hline Age (years) & $47.4(13.2)$ & $45.3(14.2)$ & $48.5(14.2)$ & $54.2(8.1)^{\dagger}$ & $42.7(9.7)$ \\
\hline Height (m) & $1.65(0.07)$ & $1.66(0.06)$ & $1.64(0.07)$ & $1.63(0.08)$ & $1.67(0.07)$ \\
\hline $\operatorname{BMI}\left(\mathrm{kg} / \mathrm{m}^{2}\right)$ & $27.1(6.0)$ & $22.3(1.8)$ & $26.9(1.2)^{\dagger}$ & $31.6(1.2)^{\dagger}$ & $40.1(3.0)^{\dagger}$ \\
\hline L1-L4 BMD $\left(\mathrm{g} / \mathrm{cm}^{2}\right)^{*}$ & $1.20(0.14)$ & $1.19(0.15)$ & $1.16(0.15)$ & $1.27(0.13)$ & $1.21(0.13)$ \\
\hline Adjusted mean ${ }^{\#}$ L1-L4 BMD $\left(\mathrm{g} / \mathrm{cm}^{2}\right)^{*}$ & $1.20(0.16)$ & $1.19(0.14)$ & $1.16(0.14)$ & $1.28(0.14)$ & $1.20(0.14)$ \\
\hline L1-L4 TBS ${ }^{*}$ & $1.37(0.11)$ & $1.39(0.09)$ & $1.39(0.13)$ & $1.31(0.10)^{\dagger}$ & $1.34(0.12)$ \\
\hline Adjusted mean ${ }^{\#}$ L1-L4 TBS ${ }^{*}$ & $1.36(0.11)$ & $1.39(0.09)$ & $1.39(0.10)$ & $1.31(0.10)$ & $1.34(0.10)$ \\
\hline
\end{tabular}

${ }^{*}$ Vertebrae excluded per ISCD recommendations

${ }^{\dagger}$ Difference significant $p \geq .05$ compared to Group A.1

${ }^{\#}$ Adjusted (univariate analysis of variance) using age as a covariate

Table 2. Correlations between variables at scan 1 (Group A, $\mathrm{n}=91$ )

\begin{tabular}{llll}
\hline & BMI & BMD & TBS \\
\hline Pearson Correlation & 1 & 0.038 & -0.242 \\
Sig. (2-tailed) & & 0.717 & 0.021 \\
Pearson Correlation & 0.038 & 1 & 0.325 \\
Sig. (2-tailed) & 0.717 & & 0.002 \\
Pearson Correlation & -0.2 & 0.325 & 1 \\
Sig. (2-tailed) & 0.021 & 0.002 & \\
\hline
\end{tabular}

Table 3. Precision results

\begin{tabular}{llllll}
\hline \multirow{2}{*}{ Group } & A & A.1 & A.2 & A.3 & A.4 \\
\cline { 2 - 6 } & Whole group & Optimum & Overweight & Obese & $>\mathbf{3 5} \mathbf{~ k g / \mathbf { m } ^ { 2 }}$ \\
\hline TBS RMSCV\% & 2.04 & 1.82 & 2.26 & 2.35 & 1.82 \\
TBS RMSSD & 0.028 & 0.025 & 0.031 & 0.031 & 0.024 \\
BMD RMSCV\% & 1.26 & 1.07 & 1.34 & 1.25 & 1.68 \\
BMD RMSSD g/cm2 & 0.015 & 0.013 & 0.016 & 0.016 & 0.020 \\
\hline
\end{tabular}

Note. $\mathrm{RMSCV} \%$ = Root mean square coefficient of variation \%; RMSSD = Root mean square standard deviation

\section{Discussion}

The results demonstrate a weak to moderate correlation of BMD with BMI, which is in line with other published data ${ }^{[21]}$. Conversely, there is a negative effect of BMI on TBS, with a weak negative correlation of $r=-0.242$ found in this study. The relatively higher BMD (n.s) and lower TBS $(p \geq .05)$ demonstrated in Group A.3 compared to the optimum BMI group is likely therefore to be attributable to the effects of increased BMI rather than to the effects of age related degenerative bone changes. The Pearson correlation between BMD and TBS was low, $r=0.325$ indicating that TBS is reflecting some bone quality properties not related to BMD, which is in accordance with previous studies ${ }^{[22]}$. 
QA for the spine phantom confirmed equipment precision error of $0.33 \%$ for L1-L4 BMD, in line with the manufacturer's tolerances and consistent with that generally expected for DXA scans. No spine phantom for TBS measurement was available for this study but ex vivo $\mathrm{CV} \%$, using 30 dry human vertebrae over three acquisitions per piece, has been reported from Medimaps' internal company data as $0.73 \%$ to $1.33 \%$ in GE Lunar Prodigy ${ }^{[23]}$. As participants will not have sustained any real change in either BMD or TBS between duplicate scans, the STPE above the baseline level of equipment error is probably attributable to minor and unavoidable changes in participants' positioning after removal and return to the scanner ${ }^{[18]}$. ISCD criteria for exclusion of abnormal vertebrae were applied in accordance with the TBS manufacturer's recommendations to avoid confounding results caused by sclerotic bone pathology due to age-related degenerative changes.

The results for the entire group of 91 participants (Group A), show STPE of $1.26 \%$ for BMD measurement. This is consistent with the $1.45 \% \mathrm{CV}$ reported by Krueger et al. ${ }^{[24]}$ for the L1-L4 ROI in a comparable precision study on GE Lunar Prodigy. The limited information on in vivo reproducibility available from Bousson et al. ${ }^{[19]}$ demonstrated a $1.2 \%$ $\mathrm{CV}$ for BMD and 1.9\% CV for TBS in 30 non-obese subjects (using the ISCD protocol) consistent with our results for BMD $(1.26 \%$ ) and the $2.04 \%$ TBS CV for the whole group of 91 participants (Group A). When Group A is split according to the BMI categories, the optimal weight group demonstrates the lowest BMD STPE and TBS STPE indicating minimal error, over and above the equipment error, resulting from positioning differences between scans. BMD STPE is poorer in the overweight and obese groups but considerably increased, although statistically non-significant, in the highest BMI category. Whilst PE is higher for TBS than for BMD in all BMI categories, the pattern of increasing TBS STPE is comparable to that of BMD STPE in the optimal and overweight/obese groups, but reduces to the level of the optimal group in the morbidly obese category. When PE is expressed as RMSSD, the same pattern is demonstrated as for RMSCV\%. Improved PE for TBS in the highest BMI category may be attributable to the application of higher exposure factors by the automatically selected thick scan mode used in $90 \%$ of this group, resulting in an improved signal to noise ratio $^{[18]}$. This reduction in TBS STPE in the $>35 \mathrm{~kg} / \mathrm{m}^{2}$ group is not reflected in the results for BMD STPE despite both BMD \& TBS being calculated from equivalent scan ROIs. This may be accounted for by the fact that BMD is calculated quantitatively from the differential attenuation of $\mathrm{x}$-rays between bone and adjacent soft tissue. Knapp et al. ${ }^{[18]}$ suggest that minor alterations in soft tissue distribution in the abdomen in fatter participants, upon repositioning, may cause changes in the soft tissue attenuation adjacent to bone in the lumbar spine ROI resulting in a small change in the BMD calculation. TBS, by contrast, is derived directly from the 2D bone image that would not be expected to be influenced by minimal soft tissue distributional changes and would be improved by increased exposure factors that would logically reduce precision error.

As TBS is becoming more widely used in a range of studies monitoring changes over time or treatment responses in various pathologies, the higher precision error for TBS needs to be taken in account and caution applied in using an LSC of $2.8 \%$. This is particularly relevant when comparing groups with different pathologies where certain medical conditions are strongly associated with higher BMI ${ }^{[25]}$.

The main limitation to this study was that it was conducted using a GE Lunar Prodigy scanner and the results may not be generalisable to other GE Lunar bone densitometers or to DXA scanners of alternative manufacture. Gluer et al. ${ }^{[26]}$ recommend a sample size of thirty participants per group for calculation of the RMSCV\% between two sets of measurements, but the group sizes for the obese and morbidly obese categories in this study were lower than required to meet this criterion. Lower sample size has potential for any outliers to distort the calculation of the CV; however the distributions for the raw TBS and BMD data were checked for groups A.3 and A.4 with no outliers found.

\section{Conclusion}

Although higher for TBS than BMD, an acceptable level of short-term PE is demonstrated in both measures that, for all BMI categories, remains below the $2.8 \%$ LSC used clinically. Nevertheless, where TBS is used to monitor changes over 
time or treatment responses, the higher precision error for TBS needs to be taken into account and caution applied in using an LSC of $2.8 \%$. STPE for both BMD and TBS are adversely affected by increasing BMI but, whilst TBS iNsight ${ }^{\circledR}$ is not recommended for use in patients exceeding a BMI of $35 \mathrm{~kg} / \mathrm{cm}^{2}, \mathrm{PE}$ is mitigated in the highest BMI category where use of the thick scanning mode improves signal to noise ratio. The results suggest that caution should be used in interpreting serial measurements, of both BMD and TBS, in obese participants and that the thick scanning mode should be ideally used for all participants with a BMI exceeding 35 even if this is not automatically applied by the scanning program. Further work would be valuable to confirm BMD and TBS STPE in a larger cohort of obese and morbidly obese participants.

\section{Disclosures}

Previous results relating to this article were presented as a poster: Hopkins SJ, Knapp KM, Parker DA, Yusof R. Short-term precision error in Dual Energy X-Ray Absorptiometry Bone-Mineral-Density and Trabecular-Bone-Score measurements; and effects of obesity. British Orthopaedic Research Society; 24-25 September; London 2012.

\section{Conflict of interests}

TBS software was supplied and licensed for free by Medimaps (Hôpital Xavier Arnozan, Avenue du Haut Lévèque, 33600 , Pessac - FRANCE) for use in this study.

\section{Acknowledgments}

The project was funded by the Society and College of Radiographers Industry Partnership Scheme (CORIPS). We would like to thank the participants for their time and input into this study and the following colleagues, who assisted with data collection: Andrew Bartlett, Sophie Holl, Soukina May, David Parker, Raihanah Yusof, David Childs and Andy Shallcross.

\section{References}

[1] Fogelman I, Blake GM. Different Approaches to Bone Densitometry. J Nucl Med. 2000; 41(12): 2015-25. PMid: 11138687.

[2] Blake GM, Wahner HW, Fogelman I. The Evaluation of Osteoporosis: Dual Energy X-ray Absorptiometry and Ultrasound in Clinical Practice. 2nd ed. London: Martin Dunitz, 1999.

[3] Marshall D, Johnell O, Wedel H. Meta-analysis of how well measures of bone mineral density predict occurrence of osteoporotic fractures. BMJ. 1996; 312(7041): 1254-9. PMid: 8634613. http://dx.doi.org/10.1136/bmj.312.7041.1254

[4] Sornay-Rendu E, Boutroy Sp, Munoz Fo, Delmas PD. Alterations of Cortical and Trabecular Architecture Are Associated With Fractures in Postmenopausal Women, Partially Independent of Decreased BMD Measured by DXA: The OFELY Study. J Bone Miner Res. 2007; 22(3): 425-33. PMid: 17181395. http://dx.doi.org/10.1359/jbmr.061206

[5] Cointry GR, Capozza RF, Negri AL, Roldan EJA, Ferretti JL. Biomechanical background for a noninvasive assessment of bone strength and muscle-bone interactions. J Musculoskelet Neuronal Interact. 2004; 4(1): 1-11. PMid: 15615073.

[6] Kreider JM, Goldstein SA. Trabecular Bone Mechanical Properties in Patients with Fragility Fractures. Clin Orthop Relat Res. 2009; 467(8): 1955-63. PMid: 19247731. http://dx.doi.org/10.1007/s11999-009-0751-8

[7] Hildebrand T, Laib A, Muller R, Dequeker J, Ruegsegger P. Direct Three-Dimensional Morphometric Analysis of Human Cancellous Bone: Microstructural Data from Spine, Femur, Iliac Crest, and Calcaneus. J Bone Miner Res. 1999; 14(7): $1167-74$. PMid: 10404017. http://dx.doi.org/10.1359/jbmr.1999.14.7.1167

[8] Boehm HF, Lutz J, Horng A, Notohamiprodjo M, Panteleon A, Pfeifer KJ, et al. Local topological analysis of densitometer-generated scan images of the proximal femur for differentiation between patients with hip fracture and age-matched controls. Osteoporos Int. 2009; 20(4): 617-24. PMid: 18685880. http://dx.doi.org/10.1007/s00198-008-0706-Z

[9] Pothuaud L, Carceller P, Hans D. Correlations between grey-level variations in 2D projection images (TBS) and 3D microarchitecture: Applications in the study of human trabecular bone microarchitecture. Bone. 2008; 42(4): 775-87. PMid: 18234577. http://dx.doi.org/10.1016/j.bone.2007.11.018

[10] Pothuaud L, Barthe N, Krieg M-A, Mehsen N, Carceller P, Hans D. Evaluation of the Potential Use of Trabecular Bone Score to Complement Bone Mineral Density in the Diagnosis of Osteoporosis: A Preliminary Spine BMD-Matched, Case-Control Study. J Clin Densitom. 2009; 12(2): 170-6. PMid: 19181553. http://dx.doi.org/10.1016/j.jocd.2008.11.006 
[11] Krueger D, Fidler E, Libber J, Aubry-Rozier B, Hans D, Binkley N. Spine Trabecular Bone Score Subsequent to Bone Mineral Density Improves Fracture Discrimination in Women. J Clin Densitom. 2013; 12(13): 78-4.

[12] Bréban S, Briot K, Kolta S, Paternotte S, Ghazi M, Fechtenbaum J, et al. Identification of Rheumatoid Arthritis Patients With Vertebral Fractures Using Bone Mineral Density and Trabecular Bone Score. J Clin Densitom. 2012; 15(3): 260-6. PMid: 22445857. http://dx.doi.org/10.1016/j.jocd.2012.01.007

[13] Boutroy S, Hans D, Sornay-Rendu E, Vilayphiou N, Winzenrieth R. Trabecular Bone Score helps classifying women at risk of fracture prospectively in the OFELY study. Osteoporos Int Suppl. 2011; 22: 362-363.

[14] Hans D, Goertzen AL, Krieg M-A, Leslie WD. Bone microarchitecture assessed by TBS predicts osteoporotic fractures independent of bone density: The Manitoba study. J Bone Miner Res. 2011; 26(11): 2762-9. PMid: 21887701. http://dx.doi.org/10.1002/jbmr.499

[15] Baim S, Wilson CR, Lewiecki EM, Luckey MM, Downs RW, Lentle BC. Precision assessment and radiation safety for dual-energy X-ray absorptiometry: position paper of the International Society for Clinical Densitometry. J Clin Densito. 2005; 8(4): 371-8. http://dx.doi.org/10.1385/JCD:8:4:371

[16] Shepherd JA, Lu Y. A Generalized Least Significant Change for Individuals Measured on Different DXA Systems. J Clin Densitom. 2007; 10(3): 249-58. PMid: 17616413. http://dx.doi.org/10.1016/j.jocd.2007.05.002

[17] Yoon JW, Choe BY, Suh TS, Lee SJ, Kim YK, Kim YM, et al. Application of a Mobile C-arm Fluoroscopy System to Bone Densitometry by Utilizing a Dual Energy X-ray Spectrum. J Korean Phys Soc. 2005; 47(3): 529-32.

[18] Knapp KM, Welsman JR, Hopkins SJ, Fogelman I, Blake GM. Obesity Increases Precision Errors in Dual-Energy X-Ray Absorptiometry Measurements. J Clin Densitom. 2012; 15(3): 315-9. PMid: 22402120. http://dx.doi.org/10.1016/j.jocd.2012.01.002

[19] Bousson V, Bergot C, Sutter B, Levitz P, Cortet B. Trabecular bone score (TBS): available knowledge, clinical relevance, and future prospects. Osteoporos Int. 2012; 23(5): 1489-1501. PMid: 22083541. http://dx.doi.org/10.1007/s00198-011-1824-6

[20] The International Society for Clinical Densitometry. Available from: http://www.iscd.org/education/resources/atlas/ (5 June 2013, date last accessed).

[21] Murillo-Uribe A, Aranda-Gallegos JE, Río de la Loza-Cava MF, et al. [Relation between body mass index and bone mineral density in a sample population of Mexican women]. Ginecol Obstet Mex. 1998; 66: 267-71. PMid: 9737066.

[22] Boutroy S, Hans D, Sornay-Rendu E, Vilayphiou N, Winzenrieth R, Chapurlat R. Trabecular bone score improves fracture risk prediction in non-osteoporotic women: the OFELY study. Osteoporos Int. 2013; 24(1): 77-85. PMid: 23070481.

http://dx.doi.org/10.1007/s00198-012-2188-2

[23] Medimaps. Available from: www.medimaps.fr/docs/view/4 (29 November 2012, date last accessed).

[24] Krueger D, Vallarta-Ast N, Checovich M, Gemar D, Binkley N. BMD Measurement and Precision: A Comparison of GE Lunar Prodigy and iDXA Densitometers. J Clin Densitom. 2012; 15(1): 21-5. PMid: 22071029.

http://dx.doi.org/10.1016/j.jocd.2011.08.003

[25] Knapp KM, Scaife L, Paisey R, Warren R, Donohoe M. Charcot Neuroarthropathy is associated with low bone mineral density. Osteoporos Int Suppl. 2012; 23S: 582-3.

[26] Glüer C, Blake G, Lu Y, Blunt B, Jergas M, Genant HK. Accurate assessment of precision errors: how to measure the reproducibility of bone densitometry techniques. Osteoporos Int. 1995; 5(4): 262-70. PMid: 7492865.

http://dx.doi.org/10.1007/BF01774016 